\title{
Audit Absensi Online Aplikasi BeeAtt Dengan Metode Cobit 4.1 Domain ME (Monitor and Evaluate) Pada PT. Prawathiya Karsa Pradiptha Bekasi
}

\author{
Muhammad Bilal Mardilla ${ }^{1}$, Anna Mukhayaroh ${ }^{2}$ \\ STMIK Nusa Mandiri \\ mbil.labil@gmail.com¹ ${ }^{1}$ anna.auh@nusamandiri.ac.id ${ }^{2}$
}

\begin{abstract}
Teknologi informasi (TI) telah menjadi tulang punggung dan elemen terpenting bagi perusahaan agar bertahan hidup serta berkesempatan dalam memperoleh keunggulan kompetitif. Begitu juga dengan PT Prawathiya Karsa Pradiptha , yang memiliki ketergantungan dengan teknologi. Konsep dasar adalah bahwa kerangka COBIT di IT Kontrol berdasarkan penentuan informasi yang diperlukan untuk mendukung tujuan bisnis dan informasi yang dihasilkan dari aplikasi gabungan dari proses TI dan sumber daya terkait. Penelitian ini membahas tata kelola IT pada aplikasi absensi online di PT Prawathiya Karsa Pradiptha , khususnya dalam sistem informasi dengan menggunakan COBIT sebagai kerangka pemantauan dan evaluasi (ME). Setelah analisis proses yang terkait dengan PT Prawathiya Karsa Pradiptha umumnya memiliki tingkat kematangan (Maturity Level) di tingkat 3 (proses didefinisikan) di mana harapan manajemen umum di tingkat 3 (proses di definisikan) sudah dapat tercapai namun masih ada beberapa hal yang harus ditingkatkan lagi. Nilai Index naik kematangan menunjukkan tingkat kedewasaan dalam setiap proses. Untuk mencapai tingkat kematangan yang PT Prawathiya Karsa Pradiptha memiliki strategi untuk mengatasi kesenjangan yang ada.

Kata Kunci : Tata Kelola TI, COBIT, Domain ME, BeeAtt
\end{abstract}

Abstract - Information technology (IT) has become the backbone and the most important element for companies to survive and have the opportunity to gain competitive advantage. Likewise with PT Prawathiya Karsa Pradiptha, which has a dependency on technology. The basic concept is that the COBIT framework in IT Control is based on determining the information needed to support business objectives and information generated from the combined application of IT processes and related resources. This study discusses IT governance in online attendance applications at PT Prawathiya Karsa Pradiptha, especially in information systems using COBIT as a monitoring and evaluation (ME) framework. After analyzing the process related to PT Prawathiya Karsa Pradiptha generally has a level of maturity (Maturity Level) at level 3 (process defined) where the expectations of general management at level 3 (the process is defined) can be achieved but there are still a few things that need to be improved again. Index value rises maturity indicates the level of maturity in each process. To reach the level of maturity that PT Prawathiya Karsa Pradiptha has a strategy to overcome the existing gaps.

Keywords: IT Governance, COBIT, Domain ME, BeeAtt

\section{PENDAHULUAN}

Perkembangan teknologi informasi pada saat ini berkembang begitu cepatnya. Sehingga sistem informasi sudah merambah hampir ke setiap bidang kehidupan kita sehari-hari, termasuk dunia bisnis dan manajemen. Pemanfaatan teknologi dan sistem informasi sudah memiliki peran yang cukup strategis di bidang bisnis dalam rangka memenangkan persaingan dalam mencapai tujuan perusahaan. Selain itu pemanfaatannya dapat juga digunakan dalam membantu absensi kehadiran.

Presensi atau Absensi adalah suatu pendataan kehadiran, bagian dari pelaporan aktivitas suatu institusi, atau komponen institusi itu sendiri yang berisi data-data kehadiran yang disusun dan diatur sedemikian rupa sehingga mudah untuk dicari dan dipergunakan apabila sewaktu-waktu diperlukan oleh pihak yang berkepentingan. (Wardoyo, Wiryadinata, \& Sagita, 2016)
Absensi sangat berpengaruh pada kinerja personal serta instansi dimana ia bekerja, yang dapat dijadikan pertimbangan terhadap tindak lanjut serta pembuatan keputusan bagi kelangsungan perkembangan instansi pada perusahaan PT Prawathiya Karsa Pradiptha telah mengembangkan dan menerapkan absensi online untuk karyawannya yang bernama aplikasi berbasis Android Beeatt.

Menurut Hermawan dalam jurnal (Husain, Prastian, \& Ramadhan, 2017) Android merupakan OS (Operating System) Mobile yang tumbuh ditengah OS lainnya yang berkembang dewasa ini. OS lainnya seperti Windows Mobile, i-Phone OS, Symbian, dan masih banyak lagi. Akan tetapi, OS yang ada ini berjalan dengan memprioritaskan aplikasi inti yang dibangun sendiri tanpa melihat potensi yang cukup besar dari aplikasi pihak ketiga.

Dengan adanya smartphone berbasis android yang saat ini begitu banyak, memungkinkan beberapa perusahaan 
memperbaharui sistemnya menggunakan smartphone android. Karena pengoperasiannya yang mudah dan dapat melakukan absensi dimana saja sehingga waktu yang dipergunakan tidak banyak terbuang.

Dalam hal penggunaan smartphone android sangatlah mudah, hampir lapisan masyarakat memiliki smartphone android. Dari yang ekonomi menengah sampai atas, dari anak kecil sampai orang dewasa memiliki smartphone android. Karena smartphone android memiliki banyak manfaat apabila dipakai untuk hal positif. Oleh karena itu, smartphone berbasis android diminati untuk mempermudah urusan seseorang dalam segala sesuatu.

Begitupun dengan sistem absensi, butuh pembaharuan yang sangat baik agar karyawan dapat absen dengan cepat dan tidak perlu antri untuk absen. Solusi yang terbaik adalah dengan menggunakan smartphone android. Sistem absensi dengan cara ini juga dapat memaksimalkan waktu perkerjaan dalam suatu perusahaan dibanding karyawan harus antri untuk tanda tangan pada form yang sudah disediakan atau antri didepan alat fingerprint. Hal ini sangat membuang waktu perkerjaan. Oleh karenanya, penggunaan android sangat diperlukan dalam pembaharuan sistem absensi.

Berdasarkan uraian di atas maka perlu adanya suatu audit sistem informasi absensi online pada PT Prawathiya Karsa Pradiptha Bekasi terhadap teknologi informasinya dengan metode COBIT 4.1 (Control Objective for Information and Related Technology) dengan pendekatan domain ME (Monitoring and Evaluation). "Pada dasarnya COBIT dikembangkan untuk membantu memenuhi berbagai kebutuhan manajemen terhadap informasi dengan menjembatani kesenjangan antara resiko bisnis, kontrol dan masalah teknik. COBIT memberikan satu langkah praktis melalui domain dan framework yang menggambarkan aktivitas IT dalam suatu struktur dan proses yang dapat disesuaikan" (Handayani, 2014)

\section{LANDASAN TEORI}

\section{A. Audit Sistem Informasi}

Menurut Swastika \& Putra (2016:20) dalam bukunya bahwa:

Audit sistem informasi merupakan proses pengumpulan dan pengevaluasian bukti untuk menentukan apakah sistem informasi telah menetapkan dan menerapkan sistem pengendalian internal yang memadai, semua asset dilindungi dengan baik dan tidak disalahgunakan serta terjaminnya integritas data, keandalan serta efektifitas dan efisiensi penyelenggaraan sistem informasi berbasis komputer.

\section{B. Presensi}

Menurut (Wardoyo et al., 2016) "Presensi adalah suatu pendataan kehadiran, bagian dari pelaporan aktivitas suatu institusi, atau komponen institusi itu sendiri yang berisi datadata kehadiran yang disusun dan diatur sedemikian rupa sehingga laporan kehadiran dapat dipergunakan apabila sewaktu-waktu diperlukan oleh pihak yang berkepentingan".

Secara umum, jenis-jenis absensi menurut cara penggunaannya dapat dikelompokkan menjadi dua menurut (Gunawan, Chandra, Khotama, Osmond, \& Andry, 2018), yaitu:

a) Absensi manual, yang merupakan cara penulisan kehadiran dengan cara menggunakan pena berupa tanda tangan.

b) Absensi non manual, yang merupakan cara penulisan kehadiran dengan menggunakan alat yang terkomputerisasi, bisa menggunakan kartu RFID ataupun fingerprint dan absen melalui smartphone

\section{Android}

Menurut Masruri \& Creativity (2015:2) dalam bukunya "Android merupakan sistem operasi berbasis linux untuk perangkat mobile yang dapat dikembangkang secara gratis atau open source".

Perkembangan andorid hingga saat ini sudah memiliki beberapa versi diantaranya dalam bukunya menurut Masruri \& Creativity (2015:4) adalah Android 1.0 (2008), Android 1.5 Cupcake (2009), Android 1.6 Donut (2009), Android 2.0 Eclair (2009), Android 2.2 Froyo (2010), Android 2.3 Gingerbread (2010), Android 3.0 Honeycomb (2011), Android 4.0 Ice Cream Sandwich (2011), Android 4.1 Jelly Bean (2012), Android 4.4 KitKat (2013), Android 5.0 Lollipop (2014), Android 6.0 Marshmallow (2015), Android 7.0 Nougat (2016), Android 8.0 Oreo (2017).

\section{COBIT}

Menurut Gondodiyoto dalam buku Andry \& Christianto (2018:9) menjelaskan bahwa COBIT adalah merupakan $A$ set of best practice (framework) bagi pengelola teknologi informasi (IT management). COBIT disusun oleh IT Governance Institute (ITGI) dan Information Systems Audit and Information Systems Audit and Control Association (ISACA), Tepatnya Information Systems Audit and Control Foundation's (ISACF) pada tahun 1992. Edisi pertamanya dipublikasikan pada tahun 1996, edisi kedua pada tahun 1998, edisi ketiga tahun 2000 (versi on-line dikeluarkan tahun 2003), edisi keempat pada Desember 2005 dan saat ini adalah edisi kelima pada 2012

\section{E. Kriteria Informasi COBIT}

Untuk mencapai tujuan bisnis, Informasi dibutuhkan untuk sesuai dengan kriteria kendali tertentu, dimana COBIT mengacu hal tersebut sebagai kebutuhan bisnis dari informasi. 
Berdasarkan kebutuhan kualitas, fiduciary dan keamanan secara luas, tujuh kriteria informasi yang berbeda dan saling overlapping menurut Andry \& Christianto (2018:3) didefinisikan sebagai berikut:

1. Effectiveness berhubungan dengan informasi harus relevan dan bersangkutan dengan proses bisnis serta diberikan secara berkala, konsisten, tepat, dan dapat digunakan.

2. Efficiency berhubungan dengan provisi dari informasi lewat penggunaan sumber daya yang optimal (paling produktif dan ekonomis).

3. Confidentiality berhubungan dengan perlindungan dari informasi sensitif dari penyebaran yang tidak terotorisasi.

4. Integrity berhubungan dengan ketepatan dan kelengkapan dan informasi serta validitasnya terhadap ekspektasi dan nilai bisnis.

5. Availability berhubungan dengan informasi tersedia saat dibutuhkan oleh proses bisnis sekarang dan seterusnya. Hal ini juga berhubungan dengan perencanan sumber daya dan kapabilitas terkait yang berhubungan dengan ketersediaan data.

6. Compliance berhubungan dengan kesesuaian dengan hukum regulasi, dan kontrak dimana proses bisnis sebagai subjek seperti peraturan kriteria bisnis dari pihak luar yang maupun pihak internal.

7. Reability berhubungan dengan provisi dari informasi yang sesuai untuk manajemen untuk mengoperasikan entitas dan melaksanakan fiduciary dan tanggung jawab governance-nya

\section{F. Domain ME}

Menurut Andry \& Christianto (2018:97) dalam bukunya menjelaskan bahwa, "Monitor and Evaluate, fokus pada masalah-masalah pengendalian yang menyeluruh yang diterapkan pada organisasi, pemeriksaan internal dan eksternal serta assurance (jaminan) dari independen dari proses-proses pemeriksaan yang telah dilakukan."

\section{Tabel 1. Domain Monitor and Evaluate}

\begin{tabular}{l|l}
\hline KODE & PROSES \\
\hline ME1 & Monitor dan Evaluasi Kinerja TI \\
ME2 & Monitor dan Evaluasi Pengendalian Internal \\
ME3 & Mendapatkan jaminan independent \\
ME4 & Penyediaan untuk tatakelola TI
\end{tabular}

Sumber: Andry \& Christianto (2018:97)

\section{G. Model Kematangan (Maturity Model)}

Dalam bukunya Andry \& Christianto (2018:18) Adapun generic maturity model yang digunakan adalah :
0. Non-existent - Tidak terdapat proses sama sekali. Organisasi/perusahaan yang belum menyadari bahwa adanya permasalahan yang harus dan mesti dikaji.

1. Initial/Ad Hoc - Ada bukti bahwa perusahaan menyadari adanya permasalahan yang harus dikaji, tetapi belum ada standarisasi. Namun, terdapat pelaksanaan pendekatan ad hoc yang berkecenderungan untuk diimplementasikan yang memiliki ketersesuaian dengan kasus. Pendekatan manajemen secara umum dilakukan dengan tidak terstruktur.

2. Repeatable but Intuitive - Proses yang ada telah berkembang sampai kepada tahap dimana prosedur yang serupa telah diikuti oleh para pekerja yang menjalankan tugas ini. Tidak adanya komunikasi atau training yang dilakukan dengan formal tentang standard procedure dan tanggung jawabnya yang jatuh kepada individu. Sering error dan adanya ketergantungan yang sangat tinggi terhadap individu.

3. Defined Process - Prosedur yang terlaksana telah didokumentasi, distandarisasi, dan dikomunikasikan melalui pelaksanaan training. Proses tersebut wajib diikuti. Tetapi, penyimpangannya tidak dapat terdeteksi. Prosedur tersebut tidak lengkap, akan tetapi terformalisasi pada practice yang berjalan sekarang.

4. Managed and measurable - Manajemen mengawasi dan mengukur tingkat kesesuaian proses yang berjalan dengan prosedur serta mengambil tindakan apabila proses terlihat tidak berjalan secara efektif. Pengembangan process dilakukan secara konstan dan menyediakan/memberikan good practice. Otomasi dan alat bantu digunakan dalam cara tertentu.

5. Optimised - Proses yang terlaksana telah di-design, dipilih, dan diatur sampai ke level pelaksanaan yang baik, berdasarkan hasil dari pengembangan atau perbaikan yang berkelanjutan serta model kematangan terhadap organisasi/perusahaan lain. IT dipergunakan secara terintegrasi untuk dapat mengotomasikan alur kerja, menyediakan tools support yang bertujuan meningkatkan nilai quality dan efektivitas, serta membuat perusahaan mudah beradaptasi. 


\section{Initial/ Repeatable Defined Manayed and \\ Non-existent AdHoc but Intuitive Process Measurable Optimised}

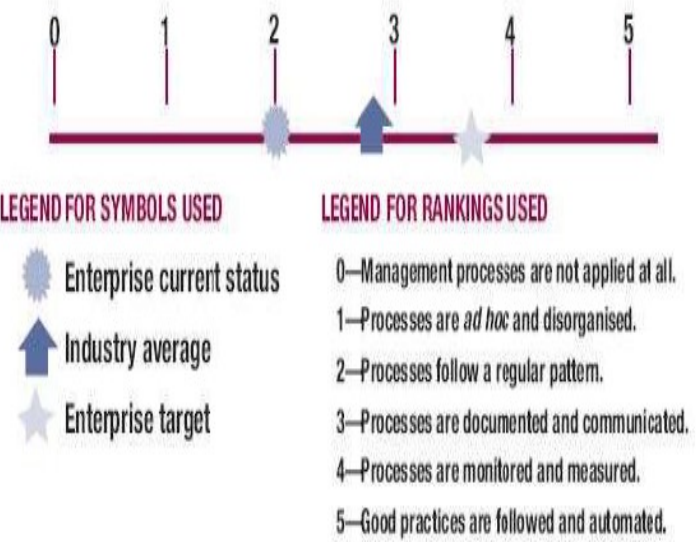

Sumber: Andry \& Christianto (2018:19)

Gambar 1 Grafik Maturity

\section{METODOLOGI PENELITIAN}

Dalam penelitian ini tahapan yang dilakukan sebagai audit absensi online dengan metode Control Objectives for Information and related Technology (COBIT) 4.1 domain monitoring and evaluation studi kasus PT Prawathiya Karsa Pradiptha Bekasi dijelaskan secara umum sebagai berikut:

1. Survey Literatur

Pada tahap awal ini penulis melakukan pencarian materi, pembuatan draf kuesioner, serta mempelajari sistem informasi yang ada di perusahaan.

2. Identifikasi Masalah

Memulai proses penelitian dengan mengidentifikasi secara langsung tentang masalah yang akan dibahas, berkaitan dengan evaluasi tata kelola teknologi informasi dengan metode Control Objectives for Information and related Technology (COBIT) 4.1 domain monitoring and evaluation studi kasus PT Prawathiya Karsa Pradiptha Bekasi berdasarkan literatur dan informasi yang diperoleh.

\section{Studi Pustaka}

Peneliti mempelajari literatur berupa tulisantulisan jurnal dan buku berkaitan dengan teori tentang tata kelola teknologi informasi dan COBIT yang akan digunakan sebagai kajian teori dalam penelitian.

4. Hipotesis

Berdasarkan identifikasi masalah dan studi pustaka terkait, peneliti memiliki hipotesis sebagai berikut:

a) Identifikasi masalah tingkat kematangan aplikasi absensi online pada PT Prawathiya Karsa Pradiptha Bekasi berada pada level 2.

b) Dari identifikasi masalah tingkat kematangan aplikasi absensi online pada
PT Prawathiya Karsa Pradiptha Bekasi berada pada level lebih besar dari 2 .

5. Menentukan Variabel dan Sumber Data

Peneliti menentukan variabel-variabel dari evaluasi tata kelola teknologi informasi dengan metode Control Objectives for Information and related Technology (COBIT) 4.1 domain monitoring and evaluation studi kasus PT Prawathiya Karsa Pradiptha Bekasi dengan berdasarkan model tingkat kematangan (maturity level) yang akan dituangkan dalam kuesioner, kemudian menentukan subjek penelitian.

Adapun variable-variabel maturity level yang terdapat pada domain monitoring and evaluation adalah sebagai berikut.

Tabel 2. Variabel Domain ME

\begin{tabular}{|c|c|}
\hline KODE & PROSES \\
\hline ME1 & $\begin{array}{l}\text { Mengawasi dan Mengevaluasi Kinerja } \\
\text { Teknologi Informasi }\end{array}$ \\
\hline ME2 & $\begin{array}{l}\text { Mengawasi dan Mengevaluasi Kontrol } \\
\text { Internal }\end{array}$ \\
\hline ME3 & Menjamin Kepatuhan Hukum \\
\hline ME4 & $\begin{array}{l}\text { Membuat Tata Kelola } \\
\text { Informasi }\end{array}$ \\
\hline
\end{tabular}

6. Observasi Lapangan dan Perizinan

Peneliti secara langsung datang ke PT Prawathiya Karsa Pradiptha Bekasi dan meminta izin kepada pihak-pihak terkait yang berwenang dalam penelitian ini adalah direktur utama PT Prawathiya Karsa Pradiptha Bekasi.

7. Mengumpulkan Data

Peneliti mengumpulkan data dengan melakukan wawancara kepada direktur utama PT Prawathiya Karsa Pradiptha Bekasi dan memberikan kuesioner kepada beberapa sampel untuk mendapatkan data yang dibutuhkan.

8. Pengolahan Data

Dalam pengolahan data akan digunakan suatu ukuran yang sudah ditentukan oleh COBIT yaitu dengan melihat tingkat kematangan (maturity level) proses agar situasi yang diinginkan dapat di ukur.

9. Menarik Kesimpulan

Peneliti menarik sebuah kesimpulan berdasarkan analisis data pada beberapa bab sebelumnya, kemudian memeriksa apakah kesimpulan sesuai dengan hipotesis, maksud dan tujuan penelitian. Selain itu memberikan saran yang dapat digunakan sebagai masukan bagi perusahaan terkait untuk dapat dimanfaatkan lebih lanjut.

\section{Metode Pengumpulan Data}

Dalam upaya mendapatkan data yang akurat, peneliti menggunakan 2 metode pengumpulan data, yaitu: 
1. Data primer dengan menggunakan observasi langsung dan wawancara:

a. Observasi

Penulis melakukan serangkaian pengumpulan data dengan mendatangi PT Prawathiya Karsa Pradiptha Bekasi untuk mengamati langsung terhadap subjek atau objek penelitian.

b. Wawancara

Wawancara dengan direktur sekaligus manager project PT Prawathiya Karsa Pradiptha Bekasi, tujuannya untuk mendapatkan informasi dan data yang berkaitan dengan penelitian secara akurat.

c. Kuesioner

Kuisioner dalam penelitian ini dirancang untuk mengetahui tingkat kematangan pengelolaan teknologi informasi yang telah digunakan oleh perusahan dengan melihat tanggapan pengguna dan pembuatan keputusan dalam menjalakan teknologi dalam perusahan tersebut.

2. Data sekunder diperoleh dengan mengumpulkan dan mengidentifikasi data, yang kemudian di olah dengan menyertakan data tertulis berdasarkan referensi beberapa buku dan jurnal yang berkaitan dengan penelitian.

\section{HASIL PENELITIAN DAN PEMBAHASAN}

Hasil penelitian ini diperoleh dengan pengumpulan data dari populasi, gambaran umum responden, rekapitulasi penilaian dan perhitungan kuesioner dari hasil tabulasi data. Seluruh komponen tersebut sangat berguna bagi penulis guna mencapai sebuah hasil pemetaan tingkat kematangan pada tata kelola teknologi informasi PT Prawathiya Karsa Pradiptha Bekasi.

\section{A. Populasi Dan Sampel Penelitian}

Populasi dalam penelitian ini diperoleh berdasarkan pihak-pihak dari PT Prawathiya Karsa Pradiptha Bekasi yang mengerti dan memahami benar mengenai segala proses tata kelola teknologi informasi pada perusahaan tersebut. Adapun pertimbangan-pertimbangan yang sesuai dengan kriteria dalam pemilihan sampel :

1. Sampel yang dipilih merupakan sampel yang memahami penerapan manajemen teknologi informasi pada PT Prawathiya Karsa Pradiptha Bekasi.

2. Sampel yang dipilih merupakan direktur, manajer, dan supervisor pada PT Prawathiya Karsa Pradiptha Bekasi.

\section{B. Gambaran Umum Responden}

Pengklasifikasian responden ditetapkan dengan cara menerima pengumpulan

data kuesioner. Responden pada penelitian ini adalah manajemen tingkat atas (top level management) yang terdiri dari direktur dan manajer, dan manajemen tingkat bawah (low level management) yang terdiri dari supervisor engineer dan supervisor network operator center. Adapun jumlah responden dalam penelitian ini berjumlah 4 orang dan dapat dilihat pada tabel berikut:

Tabel 3. Rekapitulasi Daftar Responden

\begin{tabular}{cc}
\hline Responden & Jumlah \\
\hline Direktur & 1 \\
Head IOT \& Mobile Apps & 1 \\
Sub Head IOT \& Mobile Apps & 1 \\
Programmer & 1 \\
\hline Jumlah & $\mathbf{4}$ \\
\hline
\end{tabular}

\section{Penilaian Dan Perhitungan Kuesioner}

Perancangan kuesioner dilakukan dengan memberikan sejumlah pernyataan. untuk setiap level kematangan pada domain ME (monitoring and evaluation) COBIT versi 4.1. Setiap control objective pada domain ME terdiri dari 6 level dengan urutan dari level 0 sampai dengan level 5 .

Setiap control objective domain ME pada masing-masing sub domain mempunyai beberapa pertanyaan, sehingga setiap control objective pada sub domain ME mempunyai banyak pernyataan.

Pada penentuan skoring kriteria kuesioner, penulis menggunakan skala Likert yang merefleksikan pola jawaban dengan nilai minimal 0 (nol) untuk jawaban 'Tidak ada proses', nilai 1 (satu) untuk jawaban 'Dilakukan, tetapi tidak ada prosedur', nilai 2 (dua) untuk jawaban 'Dilakukan, tetapi belum baku', nilai 3 (tiga) untuk jawaban 'Dilakukan dan sudah baku', nilai 4 (empat) untuk jawaban 'Dilakukan dengan baku dan sudah ada prosedur dan dilakukan pemantauan' dan terakhir nilai maksimal 5 (lima) untuk jawaban 'Semua proses sudah berjalan sempurna dan cepat beradaptasi terhadap perubahan'.

Berdasarkan ketentuan tersebut maka Untuk mengetahui kondisi dari setiap variabel yang diteliti, akan dilakukan deskripsi berdasarkan distribusi frekuensi dan rata-rata skor dari setiap jawaban responden. Untuk memberikan interpretasi terhadap rata-rata skor yang telah diperoleh.

\section{Perhitungan Kuesioner}

Dari setiap proses teknologi informasi (IT Process) yang ada pada COBIT, terdapat perincian control objectives yang merupakan alat kontrol dari IT process itu sendiri. Berdasarkan penelitian yang telah dilakukan, sejumlah data dikumpulkan kemudian didefinisikan dalam bentuk skor berdasarkan hasil kuesioner yang telah di isi oleh responden. 
Pendefinisian skor dibuktikan dengan penilaian (0-5). Berdasarkan hasil pengisian kuesioner oleh keempat responden maka dapat diketahui jumlah setiap butir pernyataan dengan skor Minimum 0 (Kosong) dan Maksimal 5 (lima).

Setelah data kuesioner yang telah diisi oleh keempat responden didefinisikan dalam bentuk skor, selanjutnya seluruh data tersebut baru dapat diolah untuk mencari jumlah maturity level setiap indeks tingkat kematangan.

Dalam tahap analisis agar dapat data di interpretasikan, analisis data penelitian ini dibagi menjadi 3 bagian yaitu:

1. Analisis Tingkat Kematangan Keadaan Saat Ini (current maturity)

2. Analisis Tingkat Kematangan Keadaan Yang Ingin Dicapai (expected maturity)

3. Analisis Kesenjangan (Gap Analysis)

Tabel 4. Hasil Perhitungan Maturity Level Pada ME1

\begin{tabular}{clc}
\hline Domain & \multicolumn{1}{c}{ Keterangan } & Hasil \\
\hline ME 1.1 & $\begin{array}{l}\text { Monitoring } \\
\text { approach } \\
\text { Definition and } \\
\text { collection of } \\
\text { monitoring data }\end{array}$ & 3,17 \\
ME 1.2 & $\begin{array}{l}\text { Monitoring method } \\
\text { ME 1.3 }\end{array}$ & 2,90 \\
ME 1.4 & $\begin{array}{l}\text { Performance } \\
\text { assessment }\end{array}$ & 2,40 \\
ME 1.5 & $\begin{array}{l}\text { Board and } \\
\text { executive reporting }\end{array}$ & 3,25 \\
ME 1.6 & Remedial Actions & 3,00 \\
\hline & Rata-Rata & $\mathbf{2 , 9 1}$ \\
\hline
\end{tabular}

Temuan pada ME1 adalah:

1) Monitoring sudah dilakukan secara berkala namun belum ada peningkatan kualitas dan kebijakan secara intensif.

2) Perbandingan terhadap industri dan kompetitor kunci belum ditetapkan dan dirumuskan.

3) Perusahaan sudah mempunyai kerangka kerja monitoring namun penerapannya masih belum optimal.

Rekomendasi domain ME 1 dari hasil temuan adalah:

1) Perlu adanya dokumentasi yang baik dalam setiap monitoring yang dilakukan secara berkala agar terciptanya peningkatan kualitas dan kebijakan yang lebih baik.

2) Perlu dilakukan nya Persiapan dan implementasi pengumpulan dan penilaian data berdasarkan praktek-praktek industri terbaik.

3) Perusahaan perlu melakukan perumusan agar penerapan kerangka kerja bisa di implementasikan dengan baik.
Tabel 5. Hasil Perhitungan Maturity Level Pada ME2

\begin{tabular}{clc}
\hline Domain & \multicolumn{1}{c}{ Keterangan } & Hasil \\
\hline \multirow{2}{*}{ ME 2.1 } & Monitoring of internal control & 2,50 \\
ME 2.2 & Supervisory Review & 2,00 \\
ME 2.3 & Control exceptions & 2,10 \\
ME 2.4 & Control self-assessment & 2,00 \\
ME 2.5 & Assurance of internal control & 2,50 \\
ME 2.6 & Internal control at third & 2,50 \\
ME 2.7 & Remedial actions & 2,50 \\
\hline \multicolumn{2}{c}{ Rata-Rata } & $\mathbf{2 , 3 0}$ \\
\hline
\end{tabular}

Temuan pada ME2 adalah:

1) Pengecualian pengendalian serta akar penyebab dari program absensi saat ini belum dapat diidentifikasikan secara baik.

2) Belum terdapat pengembangan terhadap program self-assessment yang berkelanjutan terhadap program absensi saat ini.

3) Perusahaan telah melakukan evaluasi pengendalian manajemen absensi namun belum dilakukan secara berkala dan penilaian serta pelaporan masih belum terdokumentasi dengan baik.

Rekomendasi pada ME2 adalah:

1) Perlu adanya identifikasi terhadap pengendalian serta akar penyebab dari program absensi saat ini.

2) Perusahaan perlu melakukan pengembangan terhadap program selfassessment yang berkelanjutan terhadap program absensi saat ini.

3) Perlu adanya evaluasi pengendalian manajemen absensi secara berkala dan dilakukan nya dokumentasi terhadap penilaian dan pelaporan yg di kumpulkan.

Tabel 6. Hasil Perhitungan Maturity Level Pada ME3

\begin{tabular}{clc}
\hline Domain & \multicolumn{1}{c}{ Keterangan } & Hasil \\
\hline ME 3.1 & $\begin{array}{l}\text { Identification of external } \\
\text { legal, regulatory and } \\
\text { contractual compliance } \\
\text { requirements }\end{array}$ & 2,00 \\
ME 3.2 & $\begin{array}{l}\text { Optimisation of response } \\
\text { to external requirements }\end{array}$ & 3,00 \\
ME 3.3 & $\begin{array}{l}\text { Evaluation of compliance } \\
\text { with external requirement }\end{array}$ & 2,00 \\
ME 3.4 & $\begin{array}{l}\text { Positive assurance of } \\
\text { compliance } \\
\text { Integrated reporting } 3.5\end{array}$ & 3,00 \\
\hline & Rata-Rata & $\mathbf{2 , 0 0}$ \\
\hline
\end{tabular}


Temuan pada ME3 adalah:

1) Belum adanya konfirmasi kepatuhan kepatuhan kebijakan hukum dan regulasi.

2) Tindakan perbaikan untuk mengatasi kesenjangan kepatuhan belum dimiliki dan belum adanya tanggung jawab dalam waktu yang tepat.

3) Perusahaan telah melakukan standar, prosedur, dan metodologi untuk memastikan bahwa hukum, peraturan dan kontrak persyaratan eksternal telah dibahas dan dikomunikasikan namun masih belum terdokumentasi dengan baik.

Rekomendasi pada ME3 adalah:

1) Segera dilakukan konfirmasi terhadap kepatuhan kebijakan hukum dan regulasi.

2) Diharapkan terdapat pengembangan terhadap kebijakan, perencanaan, dan prosedur dalam waktu dekat.

3) Diharapkan perusahaan melakukan dokumentasi terhadap peraturan dan kontrak persyaratan eksternal agar regulasi hukum dapat berjalan dengan baik.

\begin{tabular}{|c|c|c|}
\hline Domain & Keterangan & Hasil \\
\hline ME 4.1 & $\begin{array}{l}\text { Establishment of an IT } \\
\text { governance framework }\end{array}$ & 3,00 \\
\hline ME 4.2 & Strategic aligment & 2,75 \\
\hline ME 4.3 & Value delivery & 3,00 \\
\hline ME 4.4 & Resource management & 2,00 \\
\hline ME 4.5 & Risk management & 3,00 \\
\hline ME 4.6 & Performance measurement & 2,75 \\
\hline ME 4.7 & Independent assurance & 3,10 \\
\hline & Rata-Rata & 2,80 \\
\hline
\end{tabular}

Temuan pada ME4 adalah:

1) Belum terintegrasinya proses pengelolaan perusahaan dengan absensi dengan baik.

2) Dalam proses pengelolaan IT pihak manajemen belum menentukan batas toleransi proses-proses yang harus dioperasikan.

3) Dalam proses pengelolaan IT aktivitasaktivitas pengelolaan IT belum terintegrasi dengan proses pengelolaan perusahaan.

4) IT Performance indicator dalam proses pengelolaan IT belum ditetapkan.

5) IT Performance indicator dalam proses pengelolaan IT belum didokumentasikan dengan baik.

6) Permasalahan (kecelakaan) pada pengelolaan IT belum dilakukannya analisa penyebab masalah yang terjadi.

7) Permasalahan (kecelakaan) pada pengelolaan IT manajemen belum dapat mendeteksi permasalahan yang ada.
8) Manajemen belum dapat beradaptasi dengan cepat terhadap perubahan yang terjadi.

Rekomendasi pada ME4 adalah:

1) Diharapkan proses pengelolaan perusahaan dapat terintegrasi dengan baik.

2) Penentuan batas-batas toleransi proses yang harus dioperasikan dalam proses pengelolaan IT pada pihak manajemen.

3) Perlunya pengelolaan aktivitas-aktivitas yang terintegrasi dengan proses pengelolaan perusahaan.

4) Penetapan proses pengelolaan IT pada IT performance indicator.

5) Perlunya dokumentasi yang baik dalam proses pengelolaan IT pada IT performance indicator.

6) Perlunya analisa penyebab masalah yang terjadi pada pengelolaan IT.

7) Perlunya mendeteksi permasalahan yang ada pada pengelolaan IT.

8) Manajemen diharapkan dapat beradaptasi dengan cepat

\section{E. Hasil Perhitungan Maturity Level}

Kemampuan perkembangan tata kelola IT saat ini pada sistem absensi online pada PT Prawahiya Karsa Pradiptha dapat didentifikasi melalui analisis maturity level pada tingkat kematangan COBIT 4.1 dengan menggunakan domain Monitor and Evaluate (ME).

Pada analisis ini, data yang diperoleh dari hasil kuesioner dari seorang ahli di PT Prawathiya Karsa Pradiptha. Berikut adalah hasil dari proses perhitungannya:

Tabel 8. Hasil Perhitungan Maturity Level Domain ME

\begin{tabular}{clcc}
\hline Subdomain & Keterangan & Nilai & Kondisi \\
\hline ME1 & $\begin{array}{l}\text { Monitor and } \\
\text { Evaluate IT } \\
\text { Performance } \\
\text { Monitor and } \\
\text { Evaluate } \\
\text { Internal Control } \\
\text { Ensure } \\
\text { Compliance }\end{array}$ & 2,91 & $\begin{array}{c}\text { Defined } \\
\text { Process }\end{array}$ \\
ME3 & $\begin{array}{l}\text { With External } \\
\text { Requirements } \\
\text { Provide IT } \\
\text { Governance }\end{array}$ & 2,60 & $\begin{array}{c}\text { Repeatabe } \\
\text { but } \\
\text { Intuitive }\end{array}$ \\
ME4 & 2,80 & $\begin{array}{l}\text { Defined } \\
\text { Process } \\
\text { Pefined } \\
\text { Process }\end{array}$ \\
\hline Rata-Rata & $\mathbf{2 , 6 5}$ & $\begin{array}{l}\text { Defined } \\
\text { Process }\end{array}$ \\
\hline
\end{tabular}

Dari tabel diatas tersebut, dapat diketahui bahwa nilai rata-rata maturity level yang didapatkan oleh PT Prawathiya Karsa Pradiptha khususnya pada domain ME yakni sebesar 2,65 yang dianggap sudah termasuk Defined Process. 
Tabel 9. Hasil Gap Maturity Level Nilai maturity level rata-rata

\begin{tabular}{cccc} 
Domain & \multicolumn{3}{c}{ keseluruhan } \\
\cline { 2 - 4 } & Saat ini & Diharapkan & Gap \\
\hline ME & 2,65 & 3 & $3-2,65$ \\
\hline \multicolumn{3}{c}{ Hasil Gap } & $\mathbf{0 , 3 5}$ \\
\hline
\end{tabular}

Maka rata-rata expected maturity level yang diharapkan adalah pada tingkat 3 atau Defined Process. Dapat diketahui bahwa nilai kesenjangan rata-rata atau GAP rata-rata yang didapatkan dari pengurangan nilai rata-rata expected level dengan current level yang dimiliki perusahaan adalah sebesar 0,35

\section{F. Analisis GAP Maturity Level}

Target atau harapan kematangan proses tata kelola teknologi informasi dapat ditentukan dengan melihat lingkungan internal bisnis PT Prawathiya Karsa Pradiptha seperti visi dan misi, tujuan perusahaan maka dapat ditetapkan bahwa untuk dapat mendukung pencapaian tujuan PT Prawathiya Karsa Pradiptha maka expected maturity level berada pada tingkat tingkat 3 (Defined Process) pada ME1 sampai dengan ME4.

Bisa dilihat pada gambar 2.

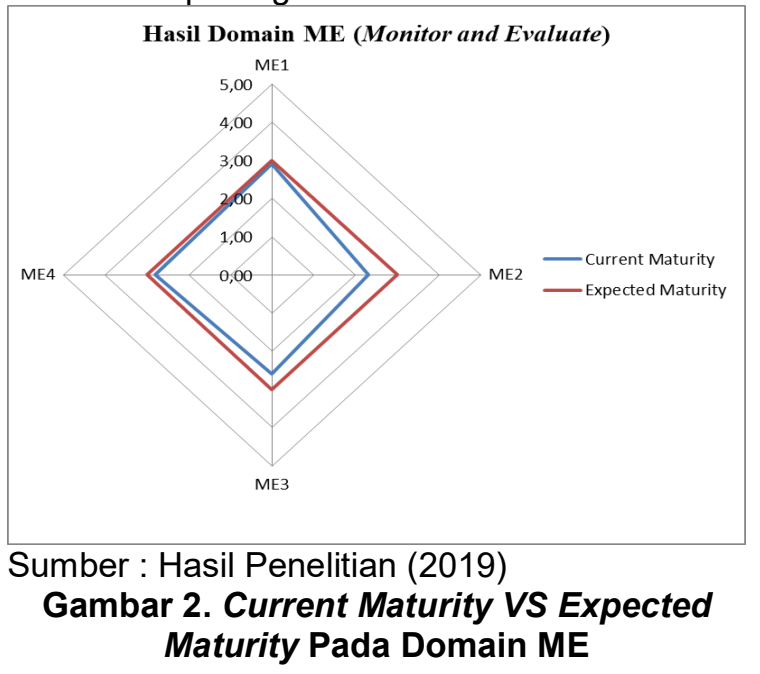

Adapun nilai maturity level dan hasil perhitungan GAP dapat dilihat pada tabel berikut:

Tabel 10. Hasil Current And Expected Maturity Level

\begin{tabular}{cccc}
\hline \multirow{2}{*}{ Domain } & \multicolumn{3}{c}{ Nilai maturity level rata-rata keseluruhan } \\
\cline { 2 - 4 } & Saat ini & Diharapkan & Gap \\
\hline ME1 & 2,91 & 3 & $3-2,91=0,09$ \\
ME2 & 2,30 & 3 & $3-2,30=0,70$ \\
ME3 & 2,60 & 3 & $3-2,60=0,40$ \\
ME4 & 2,80 & 3 & $3-2,80=0,20$ \\
\hline & Rata-Rata & & $\mathbf{0 , 3 5}$ \\
\hline
\end{tabular}

Dengan mempertimbangkan beberapa faktor tersebut, dapat diketahui bahwa tingkat kematangan yang akan menjadi acuan dalam model tata kelola teknologi informasi yang akan dikembangkan telah memiliki sejumlah indikator atau ukuran kuantitatif. Kemudian dijadikan sebagai sasaran maupun objektif kinerja setiap penerapan aplikasi teknologi informasi yang ada secara terkelola dan terukur untuk meningkatkan kualitas dalam tata kelola teknologi informasi.

\section{PENUTUP}

\section{A. Kesimpulan}

Hasil pengolahan data dari tabulasi data, rata-rata nilai kematangan domain ME (monitor and evaluate) untuk PT Prawathiya Karsa Pradiptha adalah 2,65. Ini menunjukkan bahwa dalam melaksanakan tata kelola teknologi informasi telah melakukan prosedur yang terstandarisasi, terdokumentasi, dan telah dikomunikasikan melalui pelatihan dan media. Namun masih ditemukan permasalahan pada tingkat pelaksanaan dan pemantauan secara berkala yang terlihat pada gap analysis sebesar 0,35 sehingga perlu dilakukan perbaikanperbaikan agar lebih baik kedepannya. Berdasarkan hasil penelitian dan pembahasan, maksud dan tujuan penelitian, pengolahan data, dan analisa yang telah dilakukan oleh penulis, maka dapat disimpulkan sebagai berikut:

1. Perusahaan sudah baik dalam pengkajian dan evaluasi tata kelola teknologi informasi, terlihat pada hasil maturity level telah mencapai enterprise target pada level 3. Prosedur telah distandarisasikan, didokumentasikan, serta dikomunikasikan melalui pelatihan. Namun implementasinya diserahkan pada setiap individu, sehingga kemungkinan besar penyimpangan tidak dapat di deteksi. Prosedur tersebut dikembangkan sebagai bentuk formulasi dari praktik yang ada.

2. Terdapat kepercayaan yang cukup tinggi terhadap pengetahuan individu sehingga kemungkinan tidak terjadi error cukup besar. Pengelolaan layanan teknologi informasi PT Prawathiya Karsa Pradiptha Bekasi belum melewati proses pengawasan yang cukup baik sehingga KPI (Key Performance Indicator) dan KGI (Key Goals Indicator) belum terlaksana dengan baik.

\section{B. Saran}

Dengan adanya penilaian tata kelola teknologi informasi pada aplikasi absensi yang telah dibuat pada penelitian ini, maka diharapkan PT Prawathiya Karsa Pradiptha Bekasi dapat merumuskan manajemen pengelolaan teknologi informasi dengan 
merujuk pada model tata kelola teknologi informasi yang dihasilkan tersebut.

Sebagai upaya untuk mengatasi gap yang ada saat ini, perlu ditinjau kembali kebutuhan dan penempatan beban tugas terhadap sumber daya manusia dengan mempertimbangkan untuk memberikan pelatihan dan pendidikan.

Diharapkan dengan meningkatkan kualitas sumber daya manusia yang menjadi aset perusahaan, dapat menunjang kualitas dan esensi perusahaan agar semakin berkembang.

Untuk lebih memaksimalkan kinerja layanan teknologi informasi, PT Prawathiya Karsa Pradiptha Bekasi harus mempertahankan dan terus berinovasi dalam meningkatkan kualitas kinerja terutama terkait dengan standar prosedur dan penetapan kebijakan agar sesuai dengan kebutuhan tata kelola instansi, serta merancang sebuah master plan yang digunakan untuk perencanaan dimasa mendatang disesuaikan dengan kebutuhan kinerja yang mungkin akan semakin bertambah seiring berjalannya waktu.

\section{DAFTAR PUSTAKA}

Andry, J. F., \& Christianto, K. (2018). Audit Menggunakan COBIT 4.1 dan COBIT 5 Dengan Case Study. In Yogyakarta: TEKNOSAIN.

Gunawan, C. K., Chandra, A., Khotama, M., Osmond, J., \& Andry, J. F. (2018). Audit Fingerprint pada PT $X$ dengan Framework COBIT 4.1. Jurnal Informatika Dan Sistem Informasi, 4(1), 34-43. Retrieved from https://journal.uc.ac.id/index.php/JUISI/arti cle/view/693

Handayani, R. I. (2014). Kajian Kematangan
Layanan Teknologi Informasi Pada Smkn 5tangerang Menggunakan Framework COBIT 4.0. Jurnal Pilar Nusa Mandiri, 10(1), 40-46. Retrieved from http://ejournal.nusamandiri.ac.id/index.php /pilar/article/view/461. https://doi.org/10.33480/PILAR.V10I1.74

Husain, A., Prastian, A. H. A., \& Ramadhan, A. (2017). Perancangan Sistem Absensi Online Menggunakan Android Guna Mempercepat Proses Kehadiran Karyawan Pada PT. Sintech Berkah Abadi. Technomedia Journal, 2(1), 105116. Retrieved from https://www.neliti.com/publications/267832 /perancangan-sistem-absensi-onlinemenggunakan-android-gunamempercepat-proseskehttps://doi.org/10.5281/ZENODO.13249 82

Masruri, M. H., \& Creativity, J. (2015). Buku Pintar Android. Elex Media Komputindo.

Swastika, I. P. A., Kom, M., \& Putra, I. G. L. A. R. (2016). Audit Sistem Informasi dan Tata Kelola Teknologi Informasi: Implementasi dan Studi Kasus. Penerbit Andi.

Wardoyo, S., Wiryadinata, R., \& Sagita, R. (2016). Sistem Presensi Berbasis Agoritma Eigenface Dengan Metode Principal Component Analysis. Setrum: Sistem Kendali-Tenaga-ElektronikaTelekomunikasi-Komputer, 3(1), 61-68. Retrieved from http://jurnal.untirta.ac.id/index.php/jis/articl e/view/498 